\title{
Differential response to thermal stress of shallow and deep dwelling colonies of Mediterranean red coral Corallium rubrum (L., 1758)
}

\author{
Alessandro Cau,,${ }^{1,2}$ Lorenzo Bramanti, ${ }^{3}$ Rita Cannas, ${ }^{1}$ Davide Moccia, ${ }^{1}$ Bachisio Mario Padedda, ${ }^{2}$ Cristina Porcu, ${ }^{1}$ \\ Flavio Sacco, ${ }^{1}$ Maria Cristina Follesa ${ }^{1}$

\begin{abstract}
${ }^{1}$ Department of Life and Environmental Sciences, University of Cagliari, Italy; ${ }^{2}$ Department of Architecture, Design and Urban Planning, University of Sassari, Alghero, Italy; ${ }^{3} \mathrm{CNRS}$, UMR8222, LECOB, Oceanographic Observatory, Pierre and Marie Curie University, Banyuls-sur-Mer, France

Corresponding author: alessandrocau@unica.it
\end{abstract}

\begin{abstract}
Over the last decades, the global climate change caused increase in seawater temperature, which have shown to be detrimental for Mediterranean red coral populations (Corallium rubrum). Recent researches on C. rubrum described how in shallow water habitats (i.e., up to $50 \mathrm{~m}$ depth), thermo-tolerance is influenced by local temperature fluctuations. Investigations throughout a wider bathymetric range are, however, still lacking. This work aimed at testing if $C$. rubrum colonies belonging to different populations (shallow versus deep water populations) do show different sensitivity to thermal stress. To do so, corals dwelling at different depths (32 $\mathrm{m}$ and $100 \mathrm{~m})$ were collected, kept in aquaria, and their responses to thermal stress was evaluated through two lab experiments. Oxygen consumption at different temperature regimes $\left(14^{\circ} \mathrm{C}, 21^{\circ} \mathrm{C}\right.$ and $25^{\circ} \mathrm{C}$ ) and coenosarc necrosis at $25^{\circ} \mathrm{C}$ (over a 9-day lasting experiment) were used as response variables. Shallow water samples showed significant lower oxygen consumption and coenosarc necrosis compared to deep samples, at all temperatures, revealing a potential higher survival rate in stress conditions. Significant differences in oxygen consumption between shallow and deep dwelling samples were detected in the $21^{\circ} \mathrm{C}$ treatment. Significant differences in necrosis were observed after 5 days, emphasizing a good tolerance to temperature increase for deep colonies. Implications of the obtained results for conservation of Mediterranean red corals are illustrated and discussed.
\end{abstract}

Key words: Red coral; thermal stress; oxygen consumption; animal forest.

Received: January 2018. Accepted: June 2018.

\section{INTRODUCTION}

Animals and plants can acclimatise to specific situations, adapting to environmental and biological changes; however, the impacts of the global climate change (GCC) exceed the capacity of many organisms to adapt due to their highly rapid onset (Hughes et al., 2003; Lejeusne et al., 2010; Rossi, 2013). The increase of seawater temperature is one of the major effects of GCC; according to the most recent projections, a global temperature increase of $3^{\circ} \mathrm{C}$ is forecasted by the end of the current century (Meinshausen et al., 2011; Vuuren et al., 2008). In the NW Mediterranean Sea, major mortality events of marine rocky benthic communities, especially gorgonians, have occurred in 1999 and 2003 (Cerrano et al., 2000; Di Camillo and Cerrano, 2015; Garrabou et al., 2001). Such events have been directly or indirectly related to temperature increases that overcame natural seasonal fluctuations (Ferrier-Pagès et al., 2009). Elevated temperatures reduce oxygen solubility (Truesdale et al., 1955), thus limiting its availability to benthic suspension feeders. Such reduced availability of oxygen coinciding with an increased metabolic oxygen demand may cause severe oxygen limitation in marine invertebrates under high temperatures (Previati et al., 2010).

Detrimental effects related to mass mortality events (MMEs) were observed to be 'patchy' for several species (Cerrano et al., 2000), suggesting that resistance to such stressors could show an inter-individual variability. This findings highlights the need for improving our knowledge on the different responses to thermal stress within gorgonian species (Crisci et al., 2011; Ezzat et al., 2013; Garrabou et al., 2009).

MMEs affecting the precious red coral Corallium rubrum (L., 1758) have to be considered of great regard as this Anthozoan, widely distributed in the Mediterranean Sea and neighbouring Atlantic coasts, represent a key element within the so called 'animal forests' communities (Cau et al., 2016, 2015; Rossi, 2013; Rossi et al., 2008). For C. rubrum, a range of mortality between $5 \%$ and $80 \%$ was recorded, depending on geographic locations and depth range of the affected populations, with partial to total mortality due to tissue necrosis (Cerrano et al., 2000; Di Camillo and Cerrano, 2015; Garrabou et al., 2009, 2001; Haguenauer et al., 2013). 
The bathymetric range of distribution is comprised between $5 \mathrm{~m}$ and $>1000 \mathrm{~m}$ depth (Knittweis et al., 2016), with a distinction between shallow water populations $(<50 \mathrm{~m}$ depth) and deep-water population ( $>50 \mathrm{~m}$ depth) (Cau et al., 2016; Costantini et al., 2010; Santangelo and Abbiati, 2001). Such distinction is also reflected by the genetic differentiation that characterize shallow and deep dwelling populations. These differences are due to hidden barriers like depth-dependant environmental conditions and/or the thermocline, with a threshold in connectivity placed between -40 and -50 m of depth (Cannas et al., 2016, 2015; Costantini et al., 2011; Costantini and Abbiati, 2016).

Up to date, few studies had verified the occurrence of differential thermo-tolerance among colonies of C. rubrum dwelling in different locations within shallow populations' bathymetric distribution range (i.e., comprised within $50 \mathrm{~m}$ depth) (Previati et al., 2010; Torrents et al., 2008).

As deep dwelling populations are expected to experience lower thermal fluctuations, the question has been raised as to whether colonies belonging to the two different abovementioned environments could show different capabilities in the tolerance to induced thermal stress, estimated through oxygen consumption and coenosarc necrosis pattern.

\section{METHODS}

To test the null hypothesis that shallow and deep dwelling colonies of Corallium rubrum do not have a different response to thermal stress, a total of 64 colonies were collected from central western coast of Sardinia (CW Mediterranean Sea, Italy). The two response variables evaluated to measure thermotolerance were coenosarc necrosis and oxygen consumption.

Sampling was performed by professional divers in spring 2011, at two different depths: 32 colonies were collected at $32 \mathrm{~m}$ depth (henceforth called the 'shallow samples') and 32 colonies at $100 \mathrm{~m}$ depth (henceforth called the 'deep samples'). After collection, colonies were rapidly transported to the laboratory and stored in two 100-

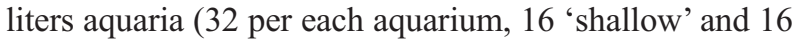
'deep') at controlled temperature $\left(14 \pm 0.5^{\circ} \mathrm{C}\right)$, salinity (37.5-38\%o) and with constant water movement $\left(1 \mathrm{~cm} \mathrm{~s}^{-1}\right)$ generated by sterile water pumps. Controlled conditions used during acclimation period were similar to those measured in situ. The acclimation period lasted a minimum of 14 days before the beginning of the experiments.

A total of 48 colonies were randomly chosen from the two aquaria and used in the oxygen consumption experiments ( 24 shallow and 24 deep colonies), while the remaining 16 were used in the necrosis experiments.

For the oxygen consumption experiment, the 42 colonies were put singularly inside glass chambers left open. The experimental design considered three treatments (Fig. 1): $14^{\circ} \mathrm{C}$ (used as control), $21^{\circ} \mathrm{C}$ and $25^{\circ} \mathrm{C}$. Selected temperature treatments were intended to simulate temperature conditions recorded in the field for shallow populations and were used in the present experiments to identify the upper thermal limits of the two populations.

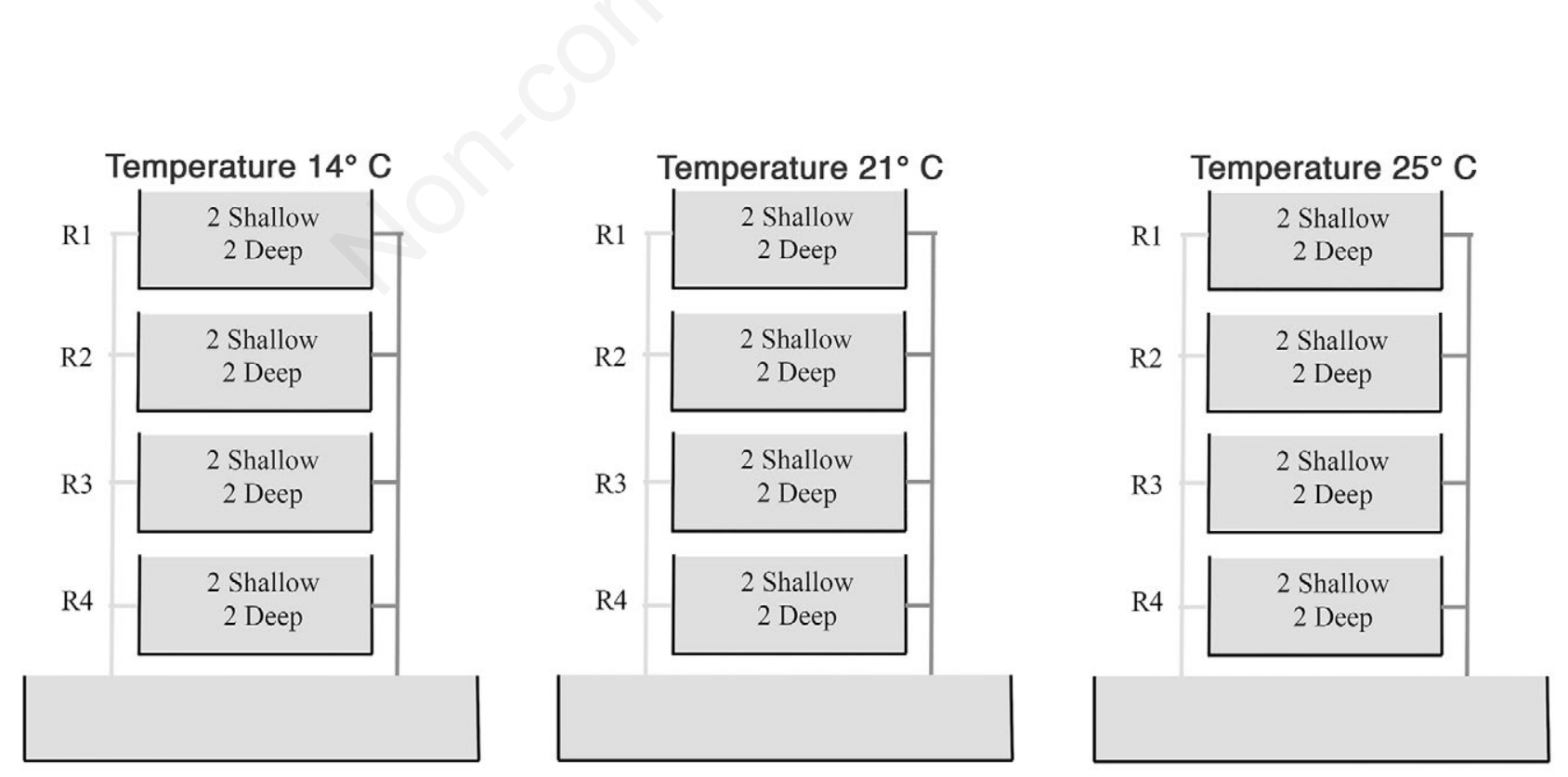

Fig. 1. Experimental design showing three aquarium sets used to carry out the thermo-tolerance experiments performed in this study. The number of shallow and deep samples used in each experiment is reported in each aquarium; each colony from deep and shallow samples is stored in a separate chamber within each replicate. Light and dark grey coloured bars represent the incoming and outgoing seawater flow. 
The experimental conditions were obtained gradually, rising temperature throughout $48 \mathrm{~h}$. When experimental conditions were reached, glass chambers were hermetically closed and the experiment started. For each treatment, four replicates were set up, each one composed by 4 colonies ( 2 shallow and 2 deep), stored separately in 4 glass chambers (Fig. 1).

Oxygen consumption was estimated as mean oxygen consumption per hour during the treatment (duration 20 hours). Oxygen level was measured with an oxymeter at the beginning and at the end of the experiment; overall, 96 measures of oxygen consumption (i.e., beginning/end of the experiment) were retrieved. Colonies were used exclusively for a single replicate in a single treatment. In addition, in order to standardize as much as possible the number of polyps for colonies used into the oxygen consumption experiment, all colonies used belonged to the same size-class (i.e., 6-7 cm in height).

For each replicate, an empty control chamber was included; the oxygen measures were performed also in the control chamber at the beginning and at the end of the experiment, in order to subtract recorded value from values registered in the chambers containing colonies. At the end of the treatment the dry mass of the coenosarcs (DMc) of each colony was measured: the colony was first weighted, then dried at $90^{\circ} \mathrm{C}$ for $24 \mathrm{~h}$, and finally weighted again after the complete removal of coenosarc (that represents the living tissue that performs respiration). The difference between the two weight measures is the dry mass.

The oxygen consumption of each colony was measured as $m g \mathrm{O}_{2} g \mathrm{DMc}^{-1} h^{-1}$, which is a mean value per hour over the total time between the initial measurement and the final measurement.

A two-way analysis of variance (ANOVA, $\alpha=0.05$ ) was performed to test the differences of the oxygen consumption between depths (shallow vs deep) and temperature regimes $\left(14^{\circ} \mathrm{C}\right.$ vs $21^{\circ} \mathrm{C}$ vs $\left.25^{\circ} \mathrm{C}\right)$. Prior to the analysis, Cochran's $\mathrm{C}$ test $(\alpha=0.05)$ was used to check the assumption of the homogeneity of variances and, whenever necessary, data were square rooted. Where data transformation did not correct violations in the assumption of homogeneous variances, an alpha-level adjustment to 0.01 was used to compensate for increased type I errors (Underwood, 1997). Secondly, in order to focus on differences in consumption between depth samples (shallow vs deep) within every temperature regime, oxygen consumptions rates were compared with the $t$-test.

Both deep and shallow stressed colonies that were used for the oxygen consumption experiment were brought back at normal thermal conditions $\left(14^{\circ} \mathrm{C}\right)$. Survival rate was retrieved after 4 weeks, calculated as overall percentage of live colonies; colonies were considered alive even only if a small part of coenosarc showed living polyps.

Finally, in order to determine potential different survivor capability to long heat stress, 8 colonies (4 shallow and 4 deep) where kept at $25^{\circ} \mathrm{C}$ temperature regime during 9 days. Every 24 h, two high definition pictures from fixed positions were taken for both sides of the colony. Pictures were analysed through CPCe software v.4.1 (Kohler and Gill, 2006) to determine the occurrence of necrosis on each colony. Necrosis was expressed as percentage of denuded axis compared to the total surface of the colony, which was obtained by both photographed sides of every colony. Eight remaining colonies not used for stress experiments (always left at $14 \pm 0.5^{\circ} \mathrm{C}$ ) were used as control.

\section{RESULTS}

Oxygen concentration at the beginning of the experiments varied from $7.49 \pm 0.13 \mathrm{mg} \mathrm{O}_{2} \mathrm{~L}^{-1}$ at $14^{\circ} \mathrm{C}$ to a minimum of $6.71 \pm 0.22 \mathrm{mg} \mathrm{O}_{2} \mathrm{~L}^{-1}$ at the highest temperature $\left(25^{\circ} \mathrm{C}\right.$; Fig. 2). For all controls, oxygen consumption did not change significantly at the beginning and at the end of each treatment ( $t$-test, Pvalue $=\mathrm{NS})$. In the chambers containing colonies the consumption rates varied between temperatures (Fig. 2); both shallow and deep colonies showed an increase in oxygen consumption at $21^{\circ} \mathrm{C}$ and, notwithstanding, a decrease at $25^{\circ} \mathrm{C}$. Focusing on the comparison between depths within treatments, the $t$-tests indicated that oxygen consumption was significantly higher in deep than in shallow colonies for the $21^{\circ} \mathrm{C}$ and $25^{\circ} \mathrm{C}$ regimes. The two-way ANOVA (Tab. 1) showed significant differences between depths and temperatures,

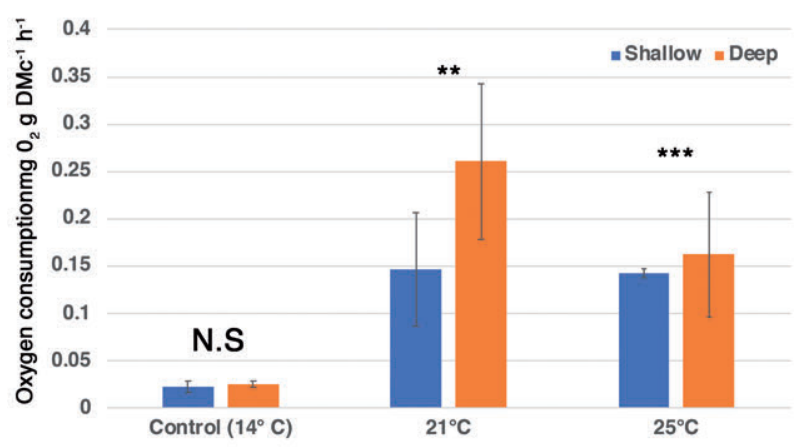

Fig. 2. Oxygen consumption measured as $\mathrm{mg} \mathrm{O} 2 \mathrm{~g} \mathrm{DMc}^{-1} \mathrm{~h}^{-1}$ (bars $\pm \mathrm{SD}$ ) for both deep (black bars) and shallow (grey bars) samples at $14^{\circ} \mathrm{C}, 21^{\circ} \mathrm{C}$ and $25^{\circ} \mathrm{C}$. The $t$-test was performed to compare oxygen consumption between deep and shallow samples. NS, not significant; ${ }^{*} \mathrm{P}<0.05 ; * * \mathrm{P}<0.01 ; * * * \mathrm{P}<0.001$. 
highlighting also a significant positive interaction between the two factors.

During the 9 days' thermal stress experiment, differences in the necrosis pattern were observed on a daily base between deep and shallow colonies. At the end of the experiment the mean percentage of necrotic tissue was significantly higher $(t$-test, $\mathrm{P}<0.05)$ for the deep sample $(84.41 \pm 11.51 \%)$ compared to the shallow sample $(31.12 \pm 18.32 \%)$. Observing the necrosis pattern progressing across days, the shallow sample showed a more linear trend with slow increment throughout all 9 days of experiment, while deep colonies increased the advancement of necrosis after day 5 . In fact, comparing the percentage of necrotic pattern of the 2 samples for each day, significant differences are reported from day 6 and for all following days (Figs. 3 and 4). As concerns the survival rate, $75 \%$ of shallow colonies survived thermal stress, while only $12.5 \%$ ( 1 colony over 8$)$ of deep colonies survived. Colonies from the control sample did not show any necrosis.

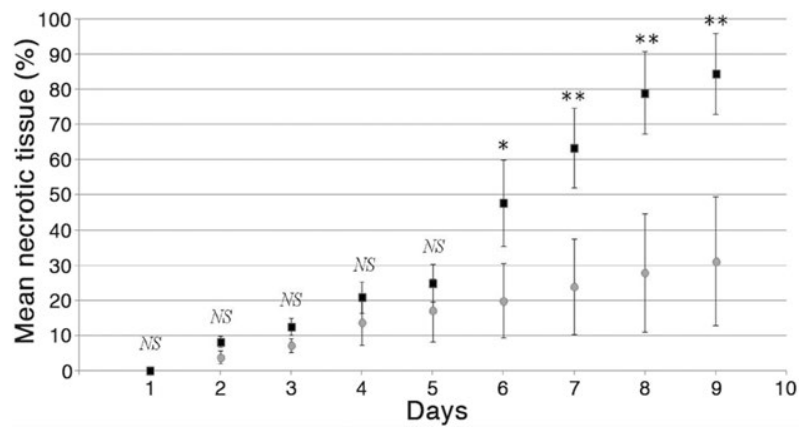

Fig. 3. Mean occurrence of necrosis for sample, detected as percentage of denuded axis (points \pm SD) for each day of treatment. Test of significant differences between samples (black squares deep sample, grey circles shallow sample at same day). NS not significant; $* \mathrm{P}<0.05 ; * * \mathrm{P}<0.01 ; * * * \mathrm{P}<0.001$.

Tab. 1. Results of the two-way ANOVA analysis on oxygen consumption.

\begin{tabular}{|c|c|c|c|c|c|}
\hline \multicolumn{6}{|l|}{ Analysis of variance } \\
\hline Source & Sum of squares & df & Mean square & Fratio & $\mathbf{P}$ \\
\hline Depth & 0.0314 & 1 & 0.0314316 & 15.37 & 0.0003 \\
\hline Temperature & 0.7701 & 2 & 0.385084 & 188.32 & 0.0000 \\
\hline \multicolumn{6}{|l|}{ Interactions } \\
\hline Depth $\mathrm{x}$ temperature & 0.0387 & 2 & 0.0193 & 9.48 & 0.0004 \\
\hline Residuals & 0.0858 & 42 & 0.002 & & \\
\hline Total (corrected) & 0.9262 & 47 & & & \\
\hline
\end{tabular}

df, degree of freedom.

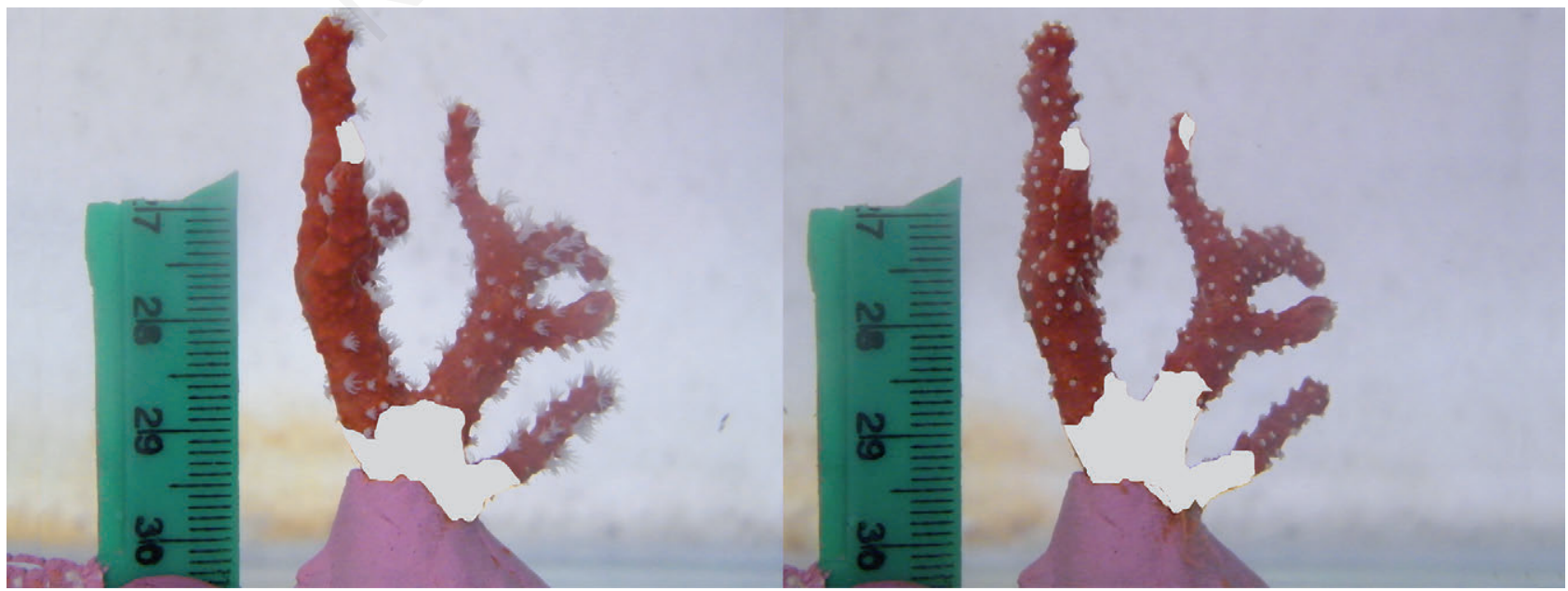

Fig. 4. Advancing necrosis in a shallow colony of C. rubrum under $25^{\circ} \mathrm{C}$ temperature regimes after 5 (left) and 9 days (right). The white area represents the necrotic tissue, measured with CPCe software. 


\section{DISCUSSION}

Several studies demonstrated that upper thermal limits of temperate corals are correlated with the environment and their previous stress history (Ezzat et al., 2013; Linares et al., 2013). The aim of this work was to test the existence of a differential tolerance to thermal stress between colonies of Corallium rubrum belonging to different populations (shallow versus deep dwelling populations). Previous studies (Torrents et al., 2008; Previati et al., 2010) investigated physiological response to thermal stress among colonies dwelling above and below the thermocline threshold, within shallow populations distribution range (up to $50 \mathrm{~m}$ depth). Our data dealt with a wider bathymetric range comprising both shallow (32 m depth) and deep dwelling colonies (100 m depth), providing empirical evidence of differential thermotolerance in C. rubrum samples from shallow and deep population. Both oxygen consumption (Fig. 2) and tissue necrosis showed significant differences between shallow and the deep samples (Figs. 3 and 4). It is a remarkable finding that colonies (both deep and shallow) survived without showing a considerable increase in oxygen consumption and a marked necrosis until the temperature that was $11^{\circ} \mathrm{C}$ higher than the control temperature. Shallow water samples showed a significant lower oxygen consumption and coenosarc necrosis at all temperatures compared to deep samples, revealing a potential higher survival rate under stress conditions. On the other hand, significant differences in oxygen consumption between shallow and deep dwelling samples were detected in the $21^{\circ} \mathrm{C}$ treatment, and after 5 days in the necrosis experiment, underlining, however, a good capacity of tolerance to temperature increase also in deep colonies. In particular, deep dwelling colonies of $C$. rubrum could be tolerant to water temperature increase that had already been observed in the deep waters of the Mediterranean basin (Haguenauer et al., 2013; Torrents et al., 2008).

Observed differences in thermo-tolerance could be explained through the strong genetic differentiation that is known to occur between shallow and deep populations of C. rubrum. In this regard, Haguenauer et al., (2013) investigated the expression of the Heat Shock Protein 70, defining marginal populations living on the edge of the species distribution in the shallow environment (dwelling at ca. $5 \mathrm{~m} \mathrm{depth)}$ as a fundamental genetic pool for evolution. Future studies, considering that the different capability to respond to thermal stress of shallow red coral populations is genetically determined should extend the investigation to deeper populations.

Moreover, in the present study the highest differences in thermo-tolerance (between shallow and deep dwelling colonies) where found in the $21^{\circ} \mathrm{C}$ treatment, but they slightly decreased at the hottest temperature $\left(25^{\circ} \mathrm{C}\right)$. Similarly to our results, investigations conducted on other species showed different responses to thermal stress with depth. In Eunicella singularis (Esper, 1794), for example, colonies dwelling in the deeper range of the bathymetric distribution of the species (below $35 \mathrm{~m}$ ) showed a higher tolerance than shallower ones (Ezzat et al., 2013; FerrierPagès et al., 2009); in addition, calcification and photosynthesis was compromised only after 14 days of high temperature exposure (Ferrier-Pagès et al., 2009). Eunicella cavolinii (Koch, 1887) showed a higher thermotolerance with no sign of necrosis after three days of exposition to $25^{\circ} \mathrm{C}$ (Previati et al., 2010) but only an alteration of the coenenchyme colour. On the other side, Paramuricea clavata (Risso, 1826) proved to be highly sensitive to high temperatures, showing a peak of polyp activity at $18^{\circ} \mathrm{C}$ and nearly complete retraction at $25^{\circ} \mathrm{C}$ (Previati et al., 2010; Cerrano et al., 2000).

In summary, the present study gives new insights suggesting the potential role of deep areas to act as 'thermal refugia' (places where colonies survive during periods of thermal stress; Bongaerts et al., 2010); this aspect is of great importance for conservation of the species as climatic change is supposed further to warm the oceans and consequently affect increasingly shallow red coral populations in the very future (Bramanti et al., 2013; Cerrano et al., 2013).

\section{AKNOWLEDGEMENTS}

Alessandro Cau gratefully acknowledges University of Sassari for the financial support of his Post Doctoral Fellowship and the Department of Life and Environmental Science of University of Cagliari for the logistic support for the aquaria experiments. In addition, all authors acknowledge all professional divers involved in the collection of samples.

\section{REFERENCES}

Bongaerts P, Ridgway T, Sampayo EM, Hoegh-Guldberg O. 2010. Assessing the "deep reef refugia" hypothesis: Focus on Caribbean reefs. Coral Reefs 29:1-19.

Bramanti L, Movilla J, Guron M, Calvo E, Gori A, DominguezCarrió C, Grinyó J. Lopez-Sanz A, Martinez-Quintana A, Pelejero C, Ziveri P, Rossi S, 2013. Detrimental effects of ocean acidification on the economically important Mediterranean red coral (Corallium rubrum). Glob. Chang. Biol. 19:1897-1908.

Cannas R, Sacco F, Cau A, Coluccia E, Follesa MC, Cau A, 2015. New insights into connectivity patterns of mesophotic red coral (Corallium rubrum) populations. Hydrobiologia 759:63-73.

Cannas R, Sacco F, Cau A, Cuccu D, Follesa MC, Cau A, 2016. Genetic monitoring of deep-water exploited banks of the precious Sardinia coral Corallium rubrum (L., 1758): useful 
data for a sustainable management. Aquat. Conserv. 26:236250.

Cau A, Bramanti L, Cannas R, Follesa MC, Angiolillo M, Canese S, Bo M, Cuccu D, Guizien K.,2016. Habitat constraints and self-thinning shape Mediterranean red coral deep population structure: implications for conservation practice. Sci. Rep. 6:23322.

Cau A, Follesa MC, Moccia D, Alvito A, Bo M, Angiolillo M, Canese S, Paliaga EM, Orrù PE, Sacco F, Cannas R, 2015. Deepwater corals biodiversity along roche du large ecosystems with different habitat complexity along the south Sardinia continental margin (CW Mediterranean Sea). Mar. Biol. 162:1865-1878.

Cerrano C, Bavestrello G, Bianchi CN, Cattaneo-vietti R, Bava S, Morganti C, Morri C, Picco P, Sara S, Schiaparelli S, Siccardi A, Sponga F, 2000. A catastrophic mass-mortality episode of gorgonians and other organisms in the Ligurian Sea (North- western Mediterranean), summer 1999. Ecol. Lett. 3:284-293.

Cerrano C, Cardini U, Bianchelli S, Corinaldesi C, Pusceddu A, Danovaro R. 2013. Red coral extinction risk enhanced by ocean acidification. Sci. Rep. 3:1457.

Costantini F, Abbiati M, 2016. Into the depth of population genetics: pattern of structuring in mesophotic red coral populations. Coral Reefs 35:39-52. 5 .

Costantini F, Rossi S, Pintus E, Cerrano C, Gili JM, Abbiati M, 2011. Low connectivity and declining genetic variability along a depth gradient in Corallium rubrum populations. Coral Reefs 30:991-1003.

Costantini F, Taviani M, Remia A, Pintus E, Schembri PJ, Abbiati M, 2010. Deep-water Corallium rubrum (L., 1758) from the Mediterranean Sea: preliminary genetic characterisation. Mar. Ecol. 31:261-269.

Crisci C, Bensoussan N, Romano JC, Garrabou J, 2011. Temperature anomalies and mortality events in marine communities: insights on factors behind differential mortality impacts in the NW Mediterranean. PLoS One 6:e23814.

Di Camillo, C.G., Cerrano, C., 2015. Mass mortality events in the NW Adriatic Sea: Phase shift from slow- to fast-growing organisms. PLoS One 10:e0126689.

Ezzat L, Merle PL, Furla P, Buttler A, Ferrier-Pagès C, 2013. The response of the Mediterranean gorgonian Eunicella singularis to thermal stress is independent of its nutritional regime. PLoS One 8:e64370.

Ferrier-Pagès C, Tambutté E, Zamoum T, Segonds N, Merle PL, Bensoussan N, Allemand D, Garrabou J, Tambutté S, 2009. Physiological response of the symbiotic gorgonian Eunicella singularis to a long-term temperature increase. J. Exp. Biol. 212:3007-3015.

Garrabou J, Coma R, Bensoussan N, Bally M, Chevaldonné P, Cigliano M, Diaz D, Marschal C, Pérez T, Ribes M, Romano JC, Serrano E, Teixido N, Torrents O, Zabala M, Zuberer F, Cerrano C, 2009. Mass mortality in Northwestern Mediterranean rocky benthic communities: Effects of the 2003 heat wave. Glob. Change Biol. 15:1090-1103.

Garrabou J, Perez T, Sartoretto S, Harmelin J, 2001. Mass mortality event in red coral Corallium rubrum populations in the Provence region (France, NW Mediterranean). Mar. Ecol. Prog. Ser. 217:263-272.

Haguenauer A, Zuberer F, Ledoux JB, Aurelle D, 2013. Adaptive abilities of the Mediterranean red coral Corallium rubrum in a heterogeneous and changing environment: From population to functional genetics. J. Exp. Mar. Bio. Ecol. 449:349-357.

Hughes TP, Baird AH, Bellwood DR, Card M, Connolly SR, Folke C, Grosberg R, Hoegh-Guldberg O, Jackson JB, Kleypas J, Lough JM, Marshall P, Nyström M, Palumbi SR, Pandolfi JM, Rosen B, Roughgarden J, 2003. Climate change, human impacts, and the resilience of coral reefs. Science 301:929-933.

Knittweis L, Aguilar R, Alvarez H, Borg JA, Evans J, Garcia S, Schembri PJ, 2016. New depth record of the precious red coral Corallium Rubrum for the Mediterranean. Proc. Congr. Int. Commission for the Scientific Exploration of the Mediterranean Sea, Kiel 41:456.

Kohler, K.E., Gill, S.M., 2006. Coral Point Count with Excel extensions (CPCe): A Visual Basic program for the determination of coral and substrate coverage using random point count methodology. Comput. Geosci. 32, 1259-1269.

Lejeusne C, Chevaldonné P, Pergent-Martini C, Boudouresque CF, Pérez T, 2010. Climate change effects on a miniature ocean: the highly diverse, highly impacted Mediterranean Sea. Trends Ecol. Evol. 25:250-260.

Linares C, Cebrian E, Kipson S, Garrabou J, 2013. Does thermal history influence the tolerance of temperate gorgonians to future warming? Mar. Environ. Res. 89:45-52.

Meinshausen M, Smith SJ, Calvin K, Daniel JS, Kainuma MLT, Lamarque JF, Matsumoto K, Montzka SA, Raper SCB, Riahi K, Thomson A, Velders GJM, Van Vuuren DP, 2011. The RCP greenhouse gas concentrations and their extensions from 1765 to 2300. Clim. Change 109:213-241.

Previati M, Scinto A, Cerrano C, Osinga R, 2010. Oxygen consumption in Mediterranean octocorals under different temperatures. J. Exp. Mar. Bio. Ecol. 390:39-48.

Rossi S, 2013. The destruction of the 'animal forests' in the oceans: Towards an over-simplification of the benthic ecosystems. Ocean Coast. Manag. 84:77-85.

Rossi S, Tsounis G, Orejas C, Padron T, Gili JM, Bramanti L, Teixido N, Gutt J, Padrón T, 2008. Survey of deep-dwelling red coral (Corallium rubrum) populations at Cap de Creus (NW Mediterranean). Mar. Biol. 154.533-545.

Santangelo G, Abbiati M, 2001. Red coral: conservation and management of an over-exploited Mediterranean species. Aquat. Conserv. 259:253-259.

Torrents O, Tambutté E, Caminiti N, Garrabou J, 2008. Upper thermal thresholds of shallow vs. deep populations of the precious Mediterranean red coral Corallium rubrum (L.): Assessing the potential effects of warming in the NW Mediterranean. J. Exp. Mar. Bio. Ecol. 357:7-19.

Truesdale GA, Downing AL, Lowden GF, 1955. The solubility of oxygen in pure water and sea-water. J. Appl. Chem. 5:53-62.

Underwood AJ, 1997. Experiments in ecology: Their Logical design and interpretation using analysis of variance. Cambridge University Press, Cambridge.

Van Vuuren DP, Meinshausen M, Plattner GK, Joos F, Strassmann KM, Smith SJ, Wigley TM, Raper SC, Riahi $\mathrm{K}$, de la Chesnaye F, den Elzen MG, Fujino J, Jiang K, Nakicenovic N, Paltsev S, Reilly JM. 2008. Temperature increase of 21 st century mitigation scenarios. P. Natl. Acad. Sci. USA 105:15258-15262. 